\title{
TEACHING AND LEARNING
}

\section{Pros and Cons of a Virtual Library Lab}

\author{
NICOLE EVA \\ University of Lethbridge Library, West Lethbridge, $A B$, Canada \\ nicole.eva@uleth.ca
}

The University of Lethbridge is a Liberal Education institution; thus, all students, including the business students, are required to take a breadth of classes across disciplines. Liberal Education 1000 is a popular way to help fulfill these requirements, as the class itself approaches critical thinking from various disciplinary perspectives. The four library lab sessions I run in this course are traditionally very interactive. With courses going online, it was a struggle reimagine how to do this in a virtual world until I discovered the power of the Zoom breakout room. Each class is a bit different, so these rooms have been used in a variety of ways.

In the first lab, the students are broken into groups of 4-5 to discuss various research questions presented to them to figure out which is the most researchable version of a question. The students then come back together as group to report out. This was fairly easily accomplished using breakout rooms instead of the usual in-person small groups. However, I noticed as I popped into the various rooms a variety of engagement levels among the students; some had turned on their cameras and mics and were happily chatting about the questions, others had cameras off but were still clearly engaged, some were just discussing the options via chat, and others did not seem to be interacting at all. This isn't entirely different than in-person smaller breakout groups, but it was definitely more prevalent online.

In the second lab, students normally work individually on a search worksheet, finding various resources on their topic from our discovery layer, subject-specific databases, and Google Scholar. The instructor circles the room, answering constant questions. It took some thinking, but dividing the class in two in order to have smaller groups of students and also having another librarian assist made it possible to be in each of the rooms and answer any questions that came up in a smaller group setting. By creating smaller groups, I had hoped that the students would feel more comfortable asking questions and that I wouldn't get overwhelmed with the number; however, far fewer students asked questions in the virtual world than in the real one. This is a shame because normally many "teachable moments" come out of the questions raised in the session, which gives me a chance to clarify or reinforce elements to the entire class.

For the third lab, breakout rooms of 4-5 were used again to allow students to discuss the validity of two articles presented, debate on which was more trustworthy, and then report back to the larger group. Finally, for the fourth lab-normally a "citation competition" where groups were given photocopied chapters, articles, websites, and encyclopedia articles and "raced" to be the first to put a correct citation for their resource on the white board-groups were provided with electronic resources, one per breakout room, and "raced" to input their citations into a class Google Doc. This worked very well, as I could easily see the progress being made by each group on the shared Doc, and students felt comfortable calling me into their rooms for help. In fact, I preferred this to the old white board method, which was often crowded and time-consuming. 
The move to online also provided me an opportunity to rethink the assessment elements for these labs. For the last few years, each week the students would hand in a reflection on what they had learned, what they remained confused about, and any other thoughts, associations, or light-bulb moments they had as a result of that week's activity. This time, the search worksheet, Moodle forum posts, and an online citation quiz made up most of their grade, with one final reflection counting for just a portion. I believe this variety is much more interesting, both to students and to me, and it is a more accurate reflection of learning.

Levels of engagement with these labs remained high, and feedback so far has been good. It is likely that some of the changes made - for example, using Google Docs for collaborative citations versus a white board - will be here to stay, as will the variety of assessments used. The move to online has been a great opportunity to rethink many of the labs' elements and ensure that they are there for a reason and serving the best pedagogical purpose. 